\title{
Research on Electrical Technology Course Reform based on Professional Certification of Engineering Education
}

\author{
Zhang Rui* \\ School of Information \& Control Engineering \\ Shenyang Jianzhu University \\ Shenyang, China \\ e-mail: arnold0110@ sina.com \\ * Corresponding Author \\ Liu Meiju \\ School of Information \& Control Engineering \\ Shenyang Jianzhu University \\ Shenyang, China \\ Wang Xin \\ School of Information \& Control Engineering \\ Shenyang Jianzhu University \\ Shenyang, China \\ Gao Enyang \\ School of Information \& Control Engineering \\ Shenyang Jianzhu University \\ Shenyang, China
}

\author{
Lü JiuYi \\ School of Information \& Control Engineering \\ Shenyang Jianzhu University \\ Shenyang, China \\ Wang Changtao \\ School of Information \& Control Engineering \\ Shenyang Jianzhu University \\ Shenyang, China \\ Kan Fenglong \\ School of Information \& Control Engineering \\ Shenyang Jianzhu University \\ Shenyang, China \\ Wang Bin \\ Northeastern University at Qinhuangdao \\ Qinhuangdao, China
}

\begin{abstract}
Taking engineering education certification as an opportunity and according to professional standard of engineering education certification, the reform plans are put forward. At first, we discuss recognition of professional engineering education certification in this paper. And professional engineering education certification is gate pass of engineering students going abroad. Then it is analyzed the current status and problems in electrical technology courses. For example, teachers lack engineering experience, teaching forms are single, teaching contents are invariable, and teaching time is shortened and so on. Next, in order to adapt to improving the quality of personnel training, combined with the characteristics of engineering education professional certification and electrical technology courses, the Electrical technology course reform researches are studied on several aspects of the teaching content, teaching methods, and assessment methods and so on. We had made some achievements. At last, we will propose next plans to improve students' capacity in engineering and the effects of teaching.
\end{abstract}

Keywords- engineering education certification; electrical technology; course reform; personnel training;international cooperation projects

\section{INTRODUCTION}

Engineering education professional certification, also called Washington Agreement, is a professional engineering certification targeting at undergraduates [1]. Engineering education accreditation is the main document recognition of engineering education in various countries to provide convenience for students to go abroad. In this paper, the recognition of engineering education professional certification, in view of engineering education certification standards to explore the problems and reform program of electrical engineering curriculum.

\section{RECOGNITION OF PROFESSIONAL ENGINEERING EDUCATION CERTIFICATION}

In the context of globalization, international projects, there are more and more international cooperation projects, which require the internationalization of engineering technology, not only requires technical personnel language communication skills, but also requires the engineering and technical personnel to meet the requirements of the country. Carry out engineering education certification, from the big direction is to promote the internationalization of engineering education, improve their competitiveness in the international, in the premise of ensuring the quality of students' engineering ability, and improve the impact of China's engineering education. Since the early age, we can take the opportunity to improve their professional development by professional certification, improve their professional influence in the community. Engineering education professional certification through means that our 
students in the domestic higher education can be recognized internationally, and in the relevant countries or regions in accordance with the requirements of the engineer, is engineering students go out of the country, and the world's line of pass. Therefore, engineering education professional certification in the international has been more and more attention.

In China, the first in 1992, the architecture, civil engineering, urban planning, engineering management, water supply and drainage engineering and construction environment and equipment engineering, 6 professional education certification assessment work. In 2006 the Ministry of Education formally established the Engineering Education Accreditation Board, and formed the engineering education certification system. In 2012, "China Engineering Education Accreditation Association" was established and it is a third party membership of Chinese Association of Science. In January 2013, Chinese Engineering Education Accreditation Association submitted to join the Washington Agreement "of the application materials, a formal application to join international engineering education bachelor's degree in recognition of organization, member of the Washington Agreement; June 2013, in South Korea held International Engineering Alliance will plenary session of the Governing Council unanimously adopted the number of Chinese who joined international engineering education bachelor's degree in recognition of organization -- the Washington Agreement applying to become associate members, show that the quality of Engineering Education in China and its security has been recognized by the international engineering education. Through the study period of 2 years, will vote again, after the unanimous vote, will become an official member of [2].

Currently, China's professional engineering education certification as the following basic requirements for engineering graduates [3]:

- Have the humanities social science quality, the social responsibility and the engineering profession morals;

- Have relevant knowledge in math, natural science, economy and management to be engaged in engineering;

- Master basic engineering knowledge and basic theoretical knowledge of this major, understand the front-end development and trend of this major;

- Have the ability to design and implement engineering experiment; able to analyze experimental results;

- Grasp the basic innovative methods, with the pursuit of innovation and the attitude and consciousness; have the ability to design the system and the process of comprehensive utilization of theory and technology, the design process can be integrated into the economic, environmental, legal, security, health, ethics and other constraints;

- Master document retrieval, data inquiry and the use of modern information technology to obtain information related to the basic method;

- Understanding of the professional and industrial production, design, research and development, environmental protection and sustainable development, policies and laws, regulations, and can be recognized by the objective world and social impact;

- Has a certain organizational management ability, expression ability and interpersonal skills, as well as the ability to play a role in the team;

- Ability to adapt to development, and to learn the correct understanding and learning ability;

- With international perspective and cross-cultural communication, competition and cooperation skills.

Many basic requirements of this regulation are abstract, but it can be seen that graduates have to have engineering practical capacity and engineering innovation capacity.

The core of engineering education is the cultivation of the students as the center and the target output oriented. China is a big country of engineering education, but not the power of engineering education, according to a survey, the total number of Chinese professional engineers is two times more than the United States; however, only $10 \%$ is in line with international engineers, and developed countries in line with the number of international engineers $60 \%$ [4]. Therefore, the quality of higher education in China has a big gap in knowledge, ability and quality, and professional certification is an effective way to improve the quality of higher education in China.

The traditional way of education, "teacher teach and students listen", because the student participation is very low, the students' autonomous learning will very low, so often the teachers talked about sweating, students playing the game in the following, sleep, learning effect very bad. And the teaching method of the pure theory is not suitable for the students to study the engineering education, so it is necessary to reform the course.

\section{PROBlems In EleCtRICAL TECHNOLOGY COURSE}

Electrical Engineering course as a professional basic course in the engineering of non-electrical engineering is to provide students with the basic knowledge of the electric power and the basis of the application of engineering technology. It has a very important role and status in the higher education of Engineering [5] [6]. Electrical engineering is a course in electrical engineering, which is a theoretical and practical course, which emphasizes the comprehensive and practical knowledge, and also emphasizes the ability of innovation, comprehensive analysis and solving practical problems.

\section{A. Teachers lack Engineering Background}

Traditional education is that teachers will teach the theory of knowledge entirely to students, but in Engineering Education Accreditation, and this is not enough, you need to have engineering experience of actual cases of teachers to teach students on the project, and most engineering colleges the teachers are graduate students, most of them from school to school, from theory to theory. Teachers only teach theoretical knowledge, and only have professional background, no practical work experience, no engineering background [7] [8]. Many teachers, especially specialized teachers, a solid theoretical basis but the actual project experience is very limited, on-site environment, equipment and technology do not know, information is not 
timely updates, it is difficult for students competent professional practice development and training. Such teaching status quo is difficult for students to complete the career planning, and career education practitioners have adequate guidance, reach the engineering professional certification standard education requirements.

\section{B. Teaching Forms are too single}

In the past, the basic form of teaching is classroom teaching, classroom teaching is generally used by teachers to teach each chapter, with the formula, the blackboard writing, students passively listen to lectures, such a teacher for 90 minutes to write, do not stop speaking, often appear the teacher is tired, students learn not go now.

Experimental teaching is teachers draw up detailed experimental steps and methods of operation, first of all experimental demonstration of the process, make students draw in gourd ladle and packet is several students in a group, often appear a students do the experiment, other students chat, play phone, go back experiment report copy is a job.

The results of the final exam, easy to cause the students to catch too tight, before the exam assault phenomenon. This teaching form is not conducive to the cultivation of students' knowledge and ability.

\section{Teaching content is invariable}

In the teaching content for many years using the same teaching materials, teaching content for several years, so there are some outdated technologies or contents. So that the students cannot through the curriculum to understand the latest developments in current engineering techniques, to learn the latest engineering technology, will cause the students entering the job cannot use learned knowledge to solve practical problems

\section{Teaching Time is Shortened Greatly}

To broaden the students' knowledge, the professional development of the teaching plan, the professional course, and the basic course of electrical technology, such as a large number of compression, resulting in electrical technology courses, and more practical and strong, therefore, in the scheduled time, it is impossible to complete the course content, and achieve the expected teaching purpose, teaching information is small, cannot teach more knowledge.

\section{CURRENT IMPROVEMENT OF ELECTRICAL TECHNOLOGY COURSE}

\section{A. At Classes}

At each class, first let the students review a lesson, let students in reviewing the old, then begin to introduce new courses, and analysis of class and class relationship, facilitating students to achieve mastery through a comprehensive study of the subject. To understand the electrical principle, law and so on, will first select some relevant practical cases for analysis, discussion, from the conclusion of the basic concepts, basic principles, basic calculation method, and expounds the basic principles in the use of attention. In the teaching of electronic components, will be the corresponding to the classroom, and combined with the actual application of the project to explain the characteristics of components. In the classroom will design some of the life related discussion questions, thinking, and students interact, improve their attention and interest. For example: the resistance, capacitance, inductance components, will be brought into the classroom, and to explain to students, when not all of the original value of the numerical works on how to read, and will give students a brief introduction to the life of our common radio work principle; when the three-phase power, will give you a life with electric common sense, and electric light connection mode, because the case close to life, so that can mobilize the enthusiasm of students learning.

\section{B. Solve Questions in Assignments After Classes}

After each chapter is over, the lesson will be a summary of homework, a problem of the individual answer after school, if it is a common problem, will be stressed in the course, deepen the impression

\section{Experiments}

After the completion of the theory, it is in the experimental part, so that the students can contact the theory and practice in time. Experiment teaching is an important part in the whole teaching process, and it is an important means to cultivate students' scientific experiment ability. The purpose is to make the students familiar with the use of the instrument, the general method and procedure of the experiment and master the ability of the students to master the basic testing method and the basic testing technique and the method of measuring data in the experiment. Through the writing of the experiment report, the students' ability to analyze and solve problems, solve the problem and experiment skills, improve students' ability to analyze and deal with the experimental data, and stimulate the students' interest in participating in the experiment. In the process of experiment, we have the purpose to cultivate students' innovative ability, thinking ability and ability to do it.

\section{Ordinary Tests}

In the learning process, conduct corresponding small tests regularly, so it is easy to promote students to seriously study, and grasp the learned knowledge to prepare for the subsequent content; through testing, understanding of the students of knowledge to grasp the situation, if the outstanding problem that class will be emphasized, deepen the students' memory.

\section{E. Multi-Evaluation Methods}

In order to promote the students' learning motivation, the assessment method does not use the final exam final results, but the use of a variety of assessment methods to determine the final score. Assessment is divided into two parts and the final exam scores, the final scores accounted for $40 \%$, accounting for $60 \%$ of the usual results. Usually results include:

- Class attendance accounts for $10 \%$ with 2 scores deducted for absence and 1 score deducted for sick leave and leave for personal affairs;

- Take homework for four times and homework accounts for $10 \%$ with 10 scores for each time, get the average score; 
- Two class tests, which account for $20 \%$ with a total score of 20 points and each test accounting for 10 scores;

- Experiment scores account for $20 \%$, and the experiment teacher give the grades and corresponding scores.

Practice has proved that: for the record of attendance and quizzes, students dare not easily skip class obviously attendance improved; improve the proportion of experimental results can promote students' hands will, so as to improve the students' operational capability of engineering; increase the engineering case of the class, which can promote students study more and more brains, the effect is very good.

\section{NEXT Plan OF CURRICUlum REFORM}

\section{A. Bring Results of Actual Electronic Contests into Class}

In the course of theoretical teaching, the results of the competition will be introduced into the classroom, and students together to analyze the competition design results, and students interact, improve students' interest; in the theory of learning, to make students based on their own interest in innovative design, cultivate their ability to move, increase students' learning motivation.

\section{B. Construct Micro-Classes}

As the teaching content of electrical technology course contains a lot of electrical concepts, theorems, laws and principles, students generally think that the theory can understand, but the problem is difficult to solve, but also a lot of compression, not enough time to exercise classes. Micro teaching is a new teaching method in recent years, which can simplify some theorems and definitions through the vivid and vivid animation.

\section{Add Reported Results}

Students can take the form of grouping, each group can choose the topic, in the form of report submitted to the final results[10]. The purpose of this section is to allow students to the library or through the network access to relevant information, to see what the latest components, which have the most recent technology, which is mainly used in what areas, what kind of role. In this way will be limited to the content of the classroom extended to the classroom. To guide the students to the library, laboratories, research in social life, gave students more hands-on opportunities, brains. Then through the exchange of sharing, improve ability of them to gather information, broaden their horizons and learn about the development trend of the contemporary new technology, to enable students to apply what they have learned, stimulates the student to study the interest in electrical technology, enhance the students' consciousness of engineering.

\section{Explore New Experiment Contents}

Electrical technology has the characteristics of wide knowledge, theory and practice, and the experiment teaching has been a very large proportion. At present, the experimental contents are more and more experimental, but the comprehensive and innovative experiments are relatively small, and cannot improve the students' ability to solve practical problems. In order to meet the requirements of engineering education professional certification, we need to reduce the basic experiments, increase the comprehensive, design of experiments, design novel experimental link, so as to cultivate students' engineering quality [11].

\section{CONCLUSIONS}

In order to adapt to the development of society, improve the quality of personnel training, combined with the characteristics of engineering education professional certification and electrical technology course, the reform researches are studied on several aspects in the teaching content, teaching methods, and assessment methods and so on. And we had obtained some good effects. However, this reform will be a continuous process, so next plans are proposed, we hope that electrical technology course reform program is more suitable for requirement of society.

\section{REFERENCES}

[1] Z. Fang, "Comparison of Engineering Education Certification Systems between Signers of Washington Agreement", Development and Evaluation of Higher Education, Vol.30, Apr. 2014, pp.66-76.

[2] M. Li, Y. Xiao, J. X.Zhang, S. Xu, "Teaching team construction of electronic information based on Engineering Education Certification", Teaching and Cultivating People, Forum of Higher Education, Vol.5, 2015, pp.14-16.

[3] Engineering education accreditation standards, Engineering Education Certification Guide (2014 Version), published by Chinese Engineering Education Accreditation Association Secretariat, Mar. 2014.

[4] P. G. Li,X. D. Xu, G. S. Chen, "Analysis on the Problems and Reasons of Undergraduate Engineering Education Practice Teaching in China", Higher engineering education research. Vol.3, 2012, pp.1-6.

[5] Wang Xin, Huang Kuan, Gao Zhijun. The Primary Users' Signals Recognition Algorithm in Cognitive Radio Networks via KPCA and Random Forest[J].ICIC Express Letters, 2015, 9(4):1083-1088.

[6] H. Y. Zhang, Y. G. Sun, "The Exploration of the Teaching Reform of Electric Engineering Course based on the Excellent Plan", China Electric Power Education, Jun. 2014, pp.62,85.

[7] S. R. Hu, H. Zhao, "Practice and Exploration of the Certification of Engineering Education in Electronic Information Engineering specialty", Journal of Wuhan University, Vol.2, Aug. 2012, pp.130-132.

[8] X. Z. Zhe, A. W. Han, "The Present Situation, problems, and countermeasures of Higher Engineering Education in China", Shanghai Journal of Educational Evaluation, Apr. 2015, pp.21-26.

[9] Y. X. Fang, "Study on guiding mode design based on micro class", Journal of Teaching and Management, Vol.2, 2015, pp.106-109.

[10] Wang Xin,Guo Lili,Ma Lina. Cooperative Spectrum Sensing Algorithm Based on Second User Selection and Random Forest Classification[J].ICIC Express Letters, Part B: Applications,2015, 6(3):845-850

[11] Y. H. Gao, H. P. Zhai, Y. Shao, S. Q. Gong, X. M. Liu Xiaoming, "Electrical Engineering Curriculum Reform for the Cultivation of Excellent Engineers", Journal of Electrical \& Electronic Education, Vol.34,Sep.2012,pp.74-79. 